\title{
Electrocatalytic Reduction of Free Chlorine at an $N, N$-Diethylaniline-grafted Carbon Electrode for Improved Sensitivity in Amperometric Detection
}

\author{
Kotaro MoriTA*† and Naoki HirayaMA*,** \\ *Department of Chemistry, Faculty of Science, Toho University, 2-2-1 Miyama, Funabashi 274-8510, Japan \\ **Research Center for Materials with Integrated Properties, Toho University, 2-2-1 Miyama, \\ Funabashi 274-8510, Japan
}

\begin{abstract}
The electrocatalytic activity of an $N, N$-diethylaniline-grafted carbon (DEA/PFC) electrode was utilized to improve the sensitivity in the cathodic detection of free chlorine. Voltammetric curves showed a well-defined cathodic peak of free chlorine on DEA/PFC, lowering the overlap with that of dissolved oxygen. Amperometric measurements were applied for the determination of free chlorine for a concentration range of 4 orders of magnitude. The results showed that measurements of the amperometric response with DEA/PFC can be used as the basis for a simple, accurate, and rapid method to determine free chlorine.
\end{abstract}

Keywords Free chlorine, electrode grafting, $N, N$-diethyl- $p$-phenylenediamine, amperometry

(Received November 26, 2016; Accepted December 1, 2016; Published January 10, 2017)

Sodium hypochlorite $(\mathrm{NaClO})$ is used for several purposes in our daily life, such as disinfection, ${ }^{1}$ bleaching, ${ }^{2}$ and an oxidizing reagent in industrial production. ${ }^{3} \mathrm{NaClO}$ dissolved in water exists as free chlorine, which is defined as dissolved gas $\mathrm{Cl}_{2}$, hypochlorous acid $\mathrm{HClO}$, and/or hypochlorite anion $\mathrm{ClO}^{-}$. Since the $\mathrm{p} K_{\mathrm{a}}$ of hypochlorous acid is $7.5,{ }^{4}$ the predominant species are $\mathrm{HClO}$ and $\mathrm{ClO}^{-}$for a neutral $\mathrm{pH}$ region. Although there is widespread use of $\mathrm{NaClO}$, there are concerns about harmful effects on the environmental and human health at high levels of exposure. ${ }^{5}$ Therefore, accurate determinations and continuous monitoring of free chlorine is extremely important from the perspective of water quality management. Several analytical methods, such as chemiluminescence, ${ }^{6}$ liquid chromatography, ${ }^{7}$ and photometric methods, ${ }^{8}$ including the use of $N, N$-diethyl- $p$-phenylenediamine (DPD), ${ }^{9}$ have been applied to determine the concentration of free chlorine in water. The determination of free chlorine using electrochemical methods will be a potential candidate for automated instruments that will be reliable and used in continuous measurement for water quality management. The electrochemical reduction of $\mathrm{HClO}$ and $\mathrm{ClO}^{-}$has mainly been reported for the determination of free chlorine using several types of working electrodes. ${ }^{10}$ For the case of carbon electrodes, there are several interferences by dissolved oxygen and trace metal ions on the cathodic detection of free chlorine. To overcome these problems, it is highly desired to induce a positive shift in free chlorine reduction in order to suppress the interference, especially the reduction of dissolved oxygen.

Recently, the catalytic activity of tertiary ammoniums or amines was reported for the electrochemical decomposition of free chlorine to chloride ion. ${ }^{11}$ The reaction mechanism presumed that the ammonium species reacts with free chlorine

$\dagger$ To whom correspondence should be addressed.

E-mail: kotaro@sci.toho-u.ac.jp to form a chloramine species as intermediates, resulting in decomposition of the chloramine species and the production of chloride accompanied by the reproduction of ammonium species. In this report, we consider the voltammetric behavior and amperometric determination of free chlorine at a carbon electrode covalently grafted with the $N, N$-diethylaniline (DEA) moiety. As a precursor, the chemical structure of DPD is particularly suitable for electrode grafting via the aryl radical reaction $^{12}$ (Fig. 1). It allows sensitive and selective determinations of free chlorine while lowering the interference of dissolved oxygen and other ions by voltammetry and amperometry.

Electrode grafting was performed as follows: after the precursor DPD $\left(5 \times 10^{-3} \mathrm{M}\right)$ was dissolved in a $1 \mathrm{M} \mathrm{HCl}$ solution at $4{ }^{\circ} \mathrm{C}$, an ice-cold $\mathrm{NaNO}_{2}$ (5 equiv.) aqueous solution was added. Then, after stirring the mixture for $10 \mathrm{~min}$ at $4{ }^{\circ} \mathrm{C}$, a freshly polished plastic formed carbon ${ }^{13}$ (PFC, BAS, $\phi=3 \mathrm{~mm}$ ) electrode was immersed into the mixture, and potential cycling was carried out from +0.5 to $-0.8 \mathrm{~V}$ vs. $\mathrm{Ag} / \mathrm{AgCl}$ (sat. $\mathrm{KCl}$ ).

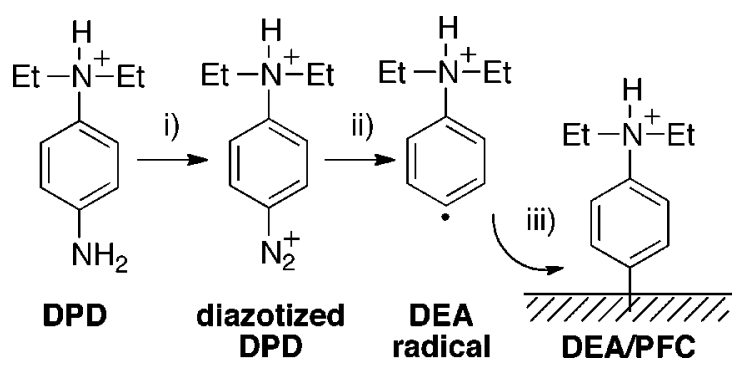

Fig. 1 Schematic representation of the electrode grafting of a carbon electrode with DPD. i) 5 eq. $\mathrm{NaNO}_{2}, 1 \mathrm{M} \mathrm{HCl}, 4^{\circ} \mathrm{C}$. ii) Electrochemical reduction. iii) Spontaneous bond formation. 


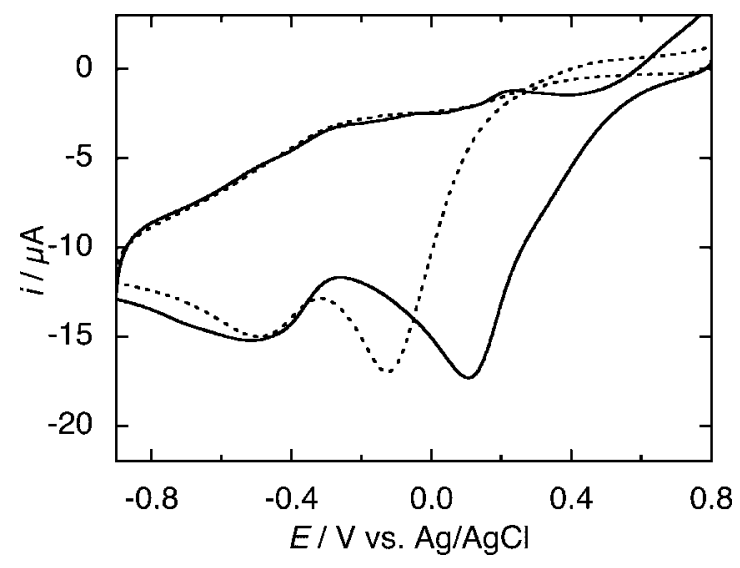

Fig. $2 \mathrm{CVs}$ of $1 \times 10^{-3} \mathrm{M} \mathrm{NaClO}$ for (solid line) the DEA/PFC and (dashed line) the bare PFC. [Phosphate], $0.05 \mathrm{M} ; \mathrm{pH} 7.0 \pm 0.1$; air satd.; room temperature; scan rate, $0.05 \mathrm{~V} \mathrm{~s}^{-1}$.

An aryl radical generated from the diazotized DPD spontaneously formed a covalent bonding to the carbon atom of the PFC electrode surface; ${ }^{14}$ then, the DEA/PFC was successfully obtained. After the electrode grafting procedure, the DEA/PFC was thoroughly rinsed and stored in water at room temperature for further use.

Figure 2 shows typical CVs of the DEA/PFC and the bare $\mathrm{PFC}$ in a $\mathrm{pH} 7$ solution containing $1 \times 10^{-3} \mathrm{M} \mathrm{NaClO}$ and $0.05 \mathrm{M}$ phosphate buffer. All measurements for $\mathrm{NaClO}$ were carried out under an air saturated aqueous buffer solution. For the case of the bare PFC, the cathodic current was observed from $c a$. $+0.2 \mathrm{~V}$, followed by a sharp peak for free chlorine at $-0.13 \mathrm{~V}$ and a broad peak for dissolved oxygen at $-0.48 \mathrm{~V}$; these two peaks were partly overlapped.

On the other hand, the cathodic peak for free chlorine was positively shifted to $+0.12 \mathrm{~V}$ at the DEA/PFC. Interestingly, the current intensity and the reduction potential of dissolved oxygen were hardly affected at the DEA/PFC. Therefore, the voltammetric result reveals that the DEA moiety is successively grafted onto the electrode surface, and the DEA/PFC shows catalytic activity for the reduction of free chlorine. According to the literature, ${ }^{11}$ the catalytic activity of alkylamines can be ascribed to the formation of the chloramine intermediate, resulting in an increase in the apparent rate constants of the reaction in the bulk phase. The catalytic activity of the DEA moiety on the PFC surface is observed as a positive shift in the reduction of free chlorine. No significant improvement in the positive shift, however, was obtained in the electrode grafting condition $^{15}$ studied in the present work, such as DPD concentration $\left(1-10 \times 10^{-3} \mathrm{M}\right)$ and the number of potential cycles $(5-20)$.

The amperometric responses of the cathodic currents to successive additions of the $\mathrm{NaClO}$ standard solution were investigated under stirred conditions $(500 \mathrm{rpm}, 50 \mathrm{~mL}$ vessel). As shown in Fig. 3, the amperometric response was clearly recognized for the DEA/PFC with an increase in the $\mathrm{NaClO}$ concentration. By changing the applied potential from $+0.1 \mathrm{~V}$ to a negative potential, an increase in the current intensity and an improvement in the upper limit of the $\mathrm{NaClO}$ concentration were observed. An increase in the background current, however, was also observed at potentials more negative than $-0.4 \mathrm{~V}$ due to the dissolved oxygen. ${ }^{16}$

The detection limit was reproducible to $c a .1 \times 10^{-6} \mathrm{M} \mathrm{NaClO}$ for three separate measurements with an applied potential of

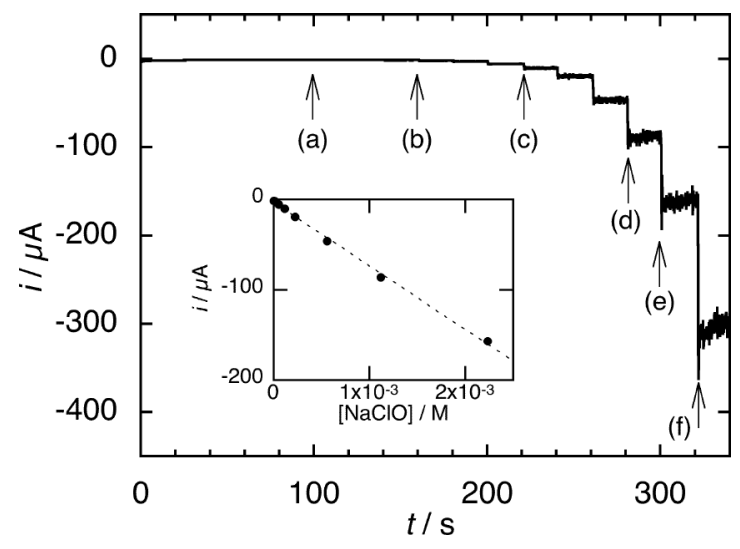

Fig. 3 Amperometric response of DEA/PFC to successive additions of a $\mathrm{NaClO}$ standard solution with an applied potential of $-0.3 \mathrm{~V}$ vs. $\mathrm{Ag} / \mathrm{AgCl}$. Final concentrations of NaClO: (a) $1.1 \times 10^{-6} \mathrm{M}$, (b) $1.1 \times$ $10^{-5} \mathrm{M}$, (c) $1.1 \times 10^{-4} \mathrm{M}$, (d) $1.1 \times 10^{-3} \mathrm{M}$, (e) $2.2 \times 10^{-3} \mathrm{M}$, and (f) $5.5 \times 10^{-3} \mathrm{M}$. [Phosphate], $0.05 \mathrm{M}$; pH $7.0 \pm 0.1$; air satd; stirring speed, $500 \mathrm{rpm}$. Inset shows current-concentration calibration plot for DEA/PFC.

Table 1 Linear ranges and detection limits for the amperometric determination of free chlorine $(n=3)$

\begin{tabular}{lccc}
\hline Electrode $^{\mathrm{a}}$ & Linear range/M & Slope/mA M & LOD/M \\
\hline Bare PFC & $5.5 \times 10^{-5}-2.2 \times 10^{-3}$ & 58.1 & $2.6 \times 10^{-5}$ \\
DEA PFC & $2.2 \times 10^{-6}-2.2 \times 10^{-3}$ & 70.4 & $1.4 \times 10^{-6}$ \\
\hline
\end{tabular}

a. Applied potential, $-0.3 \mathrm{~V}$ vs. $\mathrm{Ag} / \mathrm{AgCl}$.

$-0.3 \mathrm{~V}$. At $\sim 5 \times 10^{-3} \mathrm{M}$, the amperometric response showed a considerable decay within $10 \mathrm{~s}$ which deviated from a linear relationship. These facts defined the linear range of the present condition to be $\sim 4$ orders of magnitude. The resultant calibration plot for the $\mathrm{NaClO}$ concentration is presented in the inset of Fig. 3 and summarized in Table 1, together with results for the bare PFC. Due to the lowered background current derived from the positive shift in the free chlorine reduction, the lower limit of the linear range and the detection limit was improved for the DEA/PFC compared to the bare PFC. It also indicated that amperometric detection could work well in a wider concentration range than that of DPD titration. ${ }^{17}$ It can be said that DEA/PFC exhibits improved sensitivity over that of the bare PFC for determining the free chlorine concentration.

The effect of interfering substances on the amperometric response of the DEA/PFC toward free chlorine was also studied. To demonstrate the selectivity of DEA/PFC, interfering substances were selected from ions that are known to interfere with the DPD titrimetric and colorimetric methods, ${ }^{17}$ such as $\mathrm{Cu}^{2+}, \mathrm{Fe}^{3+}$, halogens, and $\mathrm{NO}_{2}^{-}$. The ions studied here have nearly no interference up to $1 \times 10^{-3} \mathrm{M}$ (within the change in the amperometric current intensity of $1 \%$ ) over the amperometric response for $5 \times 10^{-5} \mathrm{M} \mathrm{NaClO}$ with an applied potential of $-0.3 \mathrm{~V}$, except for $\mathrm{Cu}^{2+}$. Although a considerable amperometric current was observed for the case of $\mathrm{Cu}^{2+}$, interferences by metal ions could be decreased by the use of a positive applied potential and/or the use of masking reagents, such as EDTA. Indeed, the amperometric measurements at positive potentials were operable; calibration plots obtained with an applied potential of $\pm 0.0 \mathrm{~V}$ are depicted in Fig. 4. It is evident that the improved sensitivity can be retained for the DEA/PFC at a 


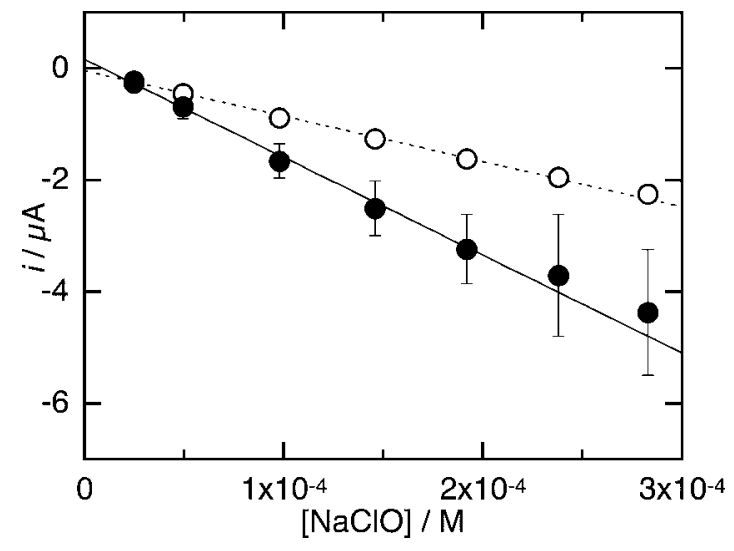

Fig. 4 Current-concentration calibration plots for (solid circle) the DEA/PFC and (open circle) the bare PFC with an applied potential of $\pm 0.0 \mathrm{~V}$ vs. Ag/AgCl. [NaClO], $2.5 \times 10^{-5}-2.8 \times 10^{-4} \mathrm{M}$; [phosphate], $0.05 \mathrm{M}$; pH $7.0 \pm 0.1$; air satd.; stirring speed, 500 rpm.

positive potential region where electrochemical reduction of metal ion is expected to be less possible. Thus, our proposed approach was found to be applicable for free chlorine detection in water under several measurement conditions.

In summary, we have shown the DEA/PFC can be used as a sensing electrode for free chlorine based on covalent grafting via aryl radical generated from DPD. The electrocatalytic activity of the DEA moiety on the electrode provides an effective positive shift in the reduction peak of free chlorine to avoid interference by dissolved oxygen, resulting in an improvement of the sensitivity for free chlorine detection. Although further improvements of the sensitivity for free chlorine as well as the selectivity over interfering ions may be necessary for the analysis of free chlorine in real samples, such as the concentration of free chlorine in commercially available bleach and continuous on-line monitoring of residual water. Due to its simplicity of the electrode grafting procedure, this kind of functionalized electrode may also be a promising candidate for various applications.

\section{Acknowledgements}

This research was supported by JSPS KAKENHI Grant Number $15 \mathrm{~K} 17874$.

\section{References}

1. H. Galal-Gorchev, Pure Appl. Chem., 1996, 68, 1731.

2. K. R. Solomon, Pure Appl. Chem., 1996, 68, 1721.

3. J. Fauvarque, Pure Appl. Chem., 1996, 68, 1713.

4. J. C. Morris, J. Phys. Chem., 1966, 70, 3798.

5. J. Miyamoto, Pure Appl. Chem., 1996, 68, 1737.

6. J. B. Claver, M. C. V. Mirón, and L. F. Capitán-Vallvey, Anal. Chim. Acta, 2004, 522, 267.

7. T. Watanabe, T. Idehara, Y. Yoshimura, and H. Nakazawa, $J$. Chromatogr. A, 1998, 796, 397.

8. J. Zhang, X. Wang, and X. Yang, Analyst, 2012, 137, 2806.

9. E. Sakurai, R. Sawamura, and A. Hamada, Eisei Kagaku (in Japanese), 1985, 31, 334.

10. F. Kodera, M. Umeda, and A. Yamada, Anal. Chim. Acta, 2005, 537, 293.

11. H. Katano, K. Uematsu, H. Tatsumi, and T. Tsukatani, Anal. Sci., 2010, 26, 349.

12. K. Morita, A. Yamaguchi, and N. Teramae, J. Electroanal. Chem., 2004, 563, 249.

13. H. Kinoshita, Y. Suda, T. Kawakubo, K. Takayama, and T. Ikeda, Microchem. J., 1994, 49, 226.

14. K. Morita, K. Shibata, H. Nagatani, N. Hirayama, and H. Imura, Anal. Sci., 2013, 29, 95.

15. K. Morita, N. Hirayama, H. Imura, A. Yamaguchi, and N. Teramae, J. Electroanal. Chem., 2011, 656, 192.

16. G. Jürmann, D. J. Schiffrin, and K. Tammeveski, Electrochim. Acta, 2007, 53, 390.

17. JIS K 0400-33-10, "Water Quality-Determination of Free Chlorine and Total Chlorine-Part 1: Titrimetric Method Using $N, N$-Diethyl-1,4-phenylenediamine", 1999, Japanese Industrial Standards Committee, Tokyo. 